\title{
Circulatory Reactions of Normotensive and Hypertensive Subjects and of the Children of Normal and Hypertensive Parents
}

\author{
R. D. Remington, Ph.D., B. Lambarth, R.N., M. Moser, M.D., ${ }^{*}$ and \\ S. W. Hoobler, M.D., Ann Arbor, Mich.
}

There is substantial agreement that high blood pressure is a familial trait. ${ }^{1-\mathrm{j}}$ The careful studies of Miall and Oldham ${ }^{1}$ and of Hamilton, Pickering, Roberts and Sowry ${ }^{2}$ indicate a higher average blood pressure among the relatives of hypertensive than of normotensive subjects. Hines, McIlhaney, and Gage; described the occurrence of hypertension in 8 pairs of identical twins, whereas in 3 pairs of fraternal twins the disease occurred in only one member. Despite these studies, few efforts have been made to identify the earliest age at which the blood pressure of the children of hypertensive parents may be expected to deviate from the values observed in the offspring of normal parents. Ayman," however, found a blood pressure in excess of $140 / 80 \mathrm{~mm}$. Hg in 29 per cent of the progeny aged 14-39 of hypertensive parents, as compared to a 3 per cent incidence of similar blood pressure elevation in the offspring of normotensive parents.

Although the familial aspects of hypertension have been agreed upon, the evidence is less consistent that exposure to various forms of stress may unduly elevate the blood pressure of prehypertensive subjects. Hines ${ }^{6}$ reported subsequent hypertension in 9 per cent of 84 normal reactors and in 54 per cent of 105 hyperreactors to an ice-water immersion test. On the other hand, Harlan ${ }^{7}$ and Armstrong and Rafferty ${ }^{8}$ could not confirm this finding. Hines also found an excessive rise in blood pressure to the cold pressor stimulus in hypertensive patients, when compared to normal control subjects. ${ }^{9.10}$ Other authors have found less consistent differences in the cold pressor responsiveness of the normal and the hypertensive subject $t^{11,12}$ or have observed considerable inconsistency in the response of the same individual to repeated testing. ${ }^{7,13}$ Other stimuli, such as breath-holding, ${ }^{14}$ exercise, ${ }^{15}$ and change in posture, ${ }^{16}$ have also been tried in a further attempt to distinguish a normal from a hypertensive response.

From the Department of Public Health Statistics and the Department of Internal Medixine. University of Michigan, Ann Arbor, Mich.

Aided by grante from the National Heart Institute, United States Puhlic Health Service

The major portion of this work is described in greater detail in a dissertation presented by Dr. Remington in partial fulfillment of the degree of Doctor of Philosophy in Public Health Statistics at the University of Michigan. A full account of the statistical methods and conclusions will be published clacwhere by the senior author.

Received for publication July 6, 1959.

*Adjunct Physician in Medicine, Montefiore Hospital, New York, $\mathrm{V} . \mathrm{K}$. 
Since there seemed to be doubt that any individual test of vascular reactivity could distinguish the overt or potentially hypertensive subject from the normal one, the present study was designed to examine the effect of four simple tests on the blood pressure of subjects with established and labile hypertension and of young individuals with and without a proved family history of the disease. In the course of such a study on blood pressure, it was also intended to learn whether the children of hypertensive parents exhibited at the teen-age level a higher blood pressure than did control subjects of similar age and sex.

\section{METIIONS}

Selection of Subjects.--Tests were performed on 50 children aged 8 to 18, one of whose parents was attending the hypertension clinic of the University of Michigan Hospital. Each individual wals then matched according to age and sex with a child who was selected from a list of students attending the Iniversity Elementary or High School, ${ }^{*}$ and an identical series of tests was then performed on the control subject in the hypertension clinic. Every effort was made to perform the tests in an identical manner, and except for the fact that the examiner usually knew to which scries the subject belonged and that the children of hypertensive parents traveled farther to reach the clinic, no important difference between the two series of tests was recognized. Whereas in the original survey, only patients of the white race were tested, it was later possible to perform a similar series of tests on Negro school children in the city of Nassau, $\nmid$ Bahamas, an area with a reported high rate of hypertension in the adult population. ${ }^{17} \mathrm{I}_{11}$ the ensuing discussion, Group I will refer to the children of the normotensive parents, Group Il the offspring of hypertensive sulfiects, and Group III will be used to designate the Bahamian school children.

For the purpose of comparing the response to the series of tests of adult subjects with and withrut hypertension, three groups were studied: 10 normotensive laboratory workers ( $N$ ), 10 patients with labile hypertension (L), and 9 subjects with an apparently established form of

Tarle I. Characteristics of the Study Groups

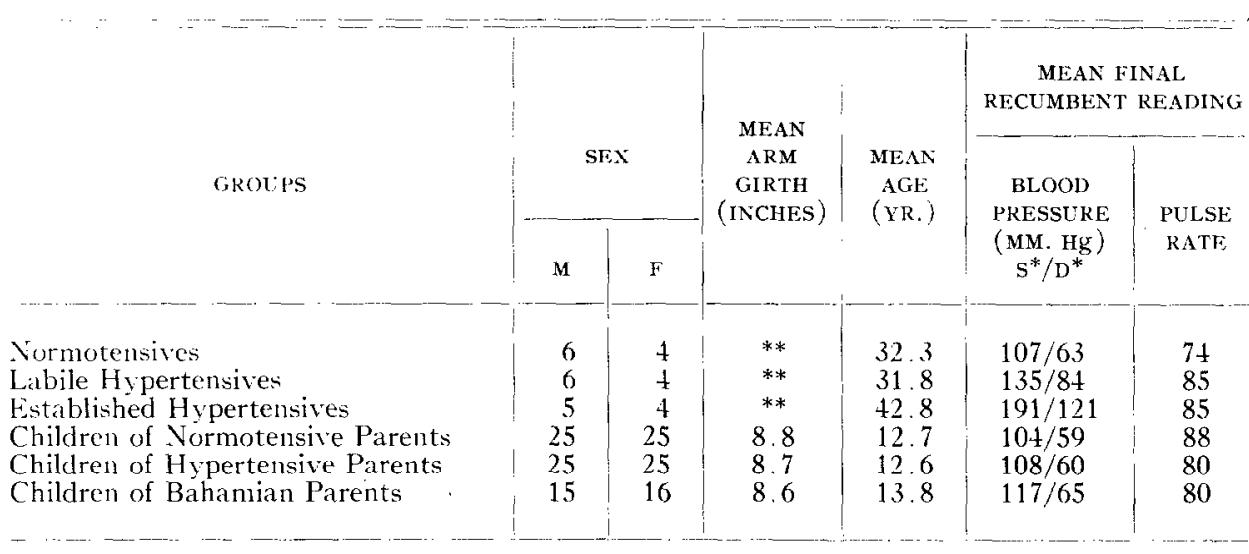

$-$

$\mathrm{RS}=$ Systolic. $\mathrm{D}=$ Diastolic

**Not recorded.

* We are indehted to Dr. Warren A. Kelcham, Courdinalor of Psychological Services, University School, and Dr. Robert S. Fox, Director of the University School, and to Dr. Norman $\mathrm{S}$. Talner and Dr. Margaret A. Lucas. school pediatricians, for permission to make the examinations.

†We wish to express our gratitude to Dr. Freda Bonner, school physician, and to Dr. E. H. Murcott. ( 'hief Medical Officer of the Bahama's Government Medical Service for their very kind cooperation in providing the facilities and assisting us in obtaining the subjects for these tests. 
the disease $(H)$. The patients with habile hypertension had records of previous casual blowl pressure readings in excess of $152 / 90 \mathrm{~mm}$. J $\lg$ (mean $=177 / 91$ ), but they were in the near-normotensive range when the tests were performed. The subjects with established hypertemsion had shown repeated and consistent elevation of the blood pressure above $168 / 98 \mathrm{~mm}$. Hg (mean resting level $=191 / 121 \%$. No patients were undergoing antihypertensive treatment at the time of testing, although one had had an unsuressful splanchnicertomy. In Table I the characteristics of the various study groups are presented.

\section{DETAILS OI: TEST PROCEDURES*}

The studies were carried out in a quiet examining room at least 1 hour postprandially. Conversation was kept to a minimum, but an easy, comfortable relationship was the goal in each case. Explanation of the procedure to be followed preceded each test, after which a 3-mintute rest period clapsed. Readings were taken in most instances by the atuthors, and after the rest period and postural test the order of administration of the cold pressor, breath-holding, and exercise tests was varied at random. The tests were applied by the same examiner and in the same order to each of the paired subjects in Groups I and II. Blood pressures were taken from the left arm, and pulse rates at the right wrist. A standard aneroid sphygmonanometer, which was frequently alibrated against a mercury manometer, wats wsed. The standard child-sive cuff (3-34 inches) wats used on two children in Group I and on three thildren in Group II. The decision to use the smaller cuff was made on the basis of arm length - the culf of width closest to two thirds of the length of the arm being chosen. The complete disappearance of sounds (Thase l'I served as the criterion for diastolic blood pressure.

Rest Period.- I'pon arriving for the series of tests, the subject entered an ramining rom where, while he was standing, his blood pressure and pulse rate were taken immediately. He then lay on the bed while the blood pressure and pulse rate were again determined. Readingst were then taken after $5,10,15$, and 20 minutes' rest; hetween determinations the subject was left alome in the room.

Postural Test.---Ner the 20-minute resting reading and a brief verbal indication that the observer would remain in the room, three recumbent readings were taken at 1-minute intervals. the last being designated as the final recumbent blood pressure. The subjert was asked to stand beside the bed, and a reading was taken immediately and every minute thereafter for 3 minutes.

Cold Pressor Test.-Following verbal instructions, a reating was taken with the subject recumbent and again after 3 minutes. The right hand was then inmersed in the ice water to a point approximately 1 inch above the wrist line, and a blood pressure reading was taken after 30 seconds and after 60 seconds of immersion. The hand was withdrawn from the water and a pulse rate was taken. Measurements were made thereafter every minute for 3 minutes. The test proredure resembled that described by Hines, "' except for the abbrevinted rest period.

Breath-Holding Test.- The subjert was seated in a comfortable chair and given verbal instructions, including a warning not to strain, in order to avoid the possibility of a Valsalva effect. A reading was taken at the beginning and end of a 3 -minute rest period. It the end of a normal expiration the subject was asked to stop breathing. The procedure was timed so that systolic: and diastolic readings were taken after approximately 20 seconds of breath-holding. This generally meant that the systolic level was recorded just before, and the diatstolic just after, the intended interval, so that the total holding time was slightly wer 20 seconds. Iuring the recovery period following the breath-holding stimulus, three readings were taken at 1 -minute intervals. Our procedure differed from that of Ayman and Goldshines: in that they used separate periods of breath-holding to determine the systolic and the diastolic blesd pressure. Mlthough the accuracy of meatsurement is improved by their method, the interpretation of results is more difficult beratuse of the double stimulus.

* A further description of the procelure, with enumeration of the successive blood pressure readings to correspond to the numbers in ligs. $2-4$, is included in the appendix. rate.

tHereafter "reading" will signify a determination of systolic and diastolic blood pressure and pulse 
Exercise Test.-Following appropriate instructions to the subjects, blond pressure reatdings were taken before and after a 3 -minute rest period with the subjects in the seated position. Then the subject stood, hands on hips, and alternately flexed and straightened his knees in time with a metronome 30 times in 60 seconds. The blood pressure and pulse rate were taken with the sulject in the seated position immediately after and at 1 -minute intervals for 3 minutes following the stimulus.

Definition of Terms.- - lest responses were alculated from the difference between blond pressure and pulie rates inmediately before and at the time of maximal stimulation. In the postural test the lirst reading taken with the subject standing erect was compared to the last measurement in recumbency. The response to rest was defined as the difference between the first and the last recumbency readings obtained 2.3 minutes later.

\section{RESPONSE TO TESTS OF ADULT SUBUECTS}
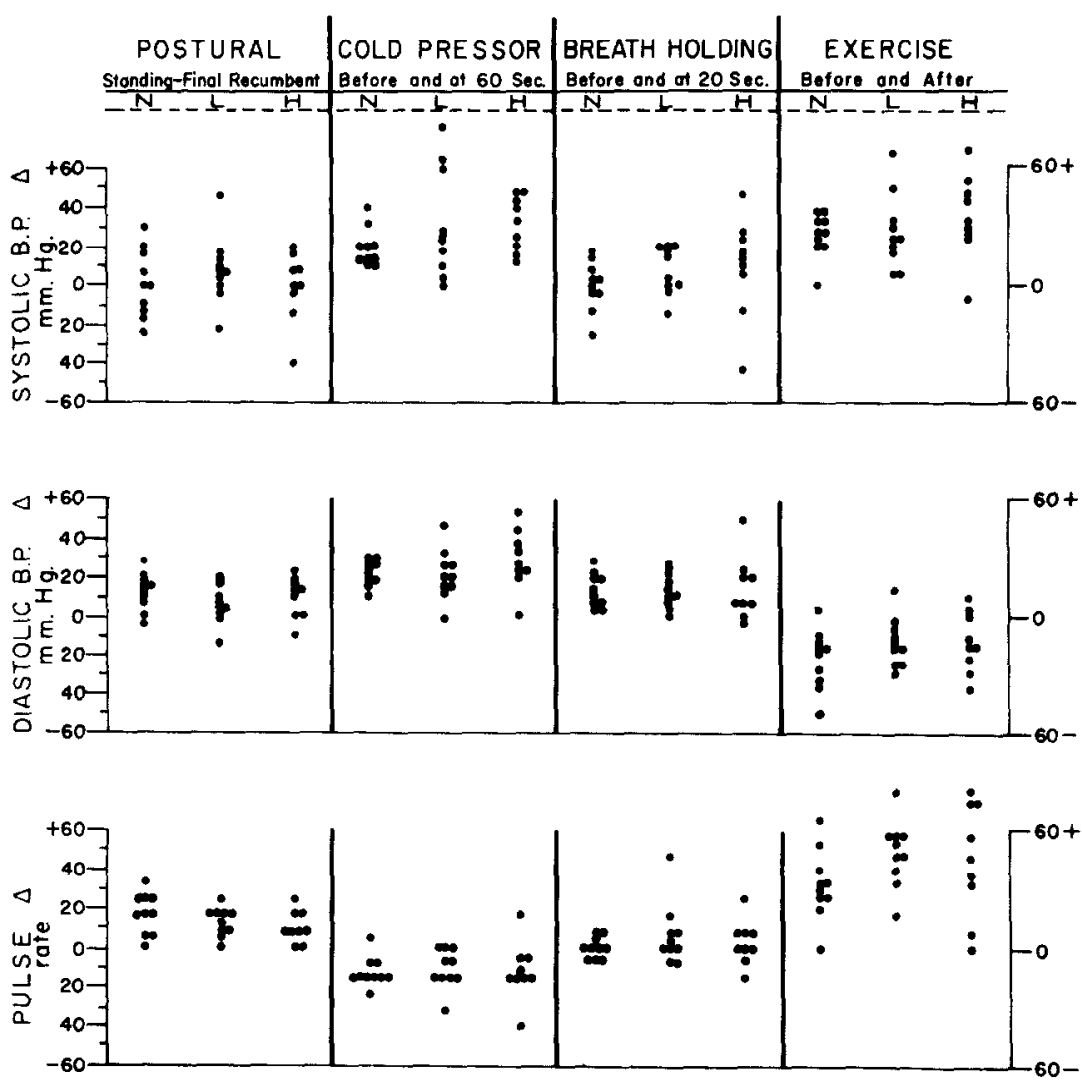

Fig. 1.--The entire test series was performed on 10 normotensive ( $N$-first column), on 10 labile ( $L$-second column), and on 9 established hypertensive ( $H$-third column) subjects. The vertical scale represents change $(\Delta)$ in blood pressure and pulse following the application of the various tests.

\section{OBSERVATIONS}

a. Reproducibility of the Tests.-In order to estinate the degree of reproducibility in the same person the tests, with the exception of the postural test, were performed on four medical students on six occasions in a randomly selected order of administration. There was no apparent day-to-day variation in the responses 
and no evidence of a systematic effect of any one test on subsequent ones. The mean systolic, diastolic, and pulse responses and standard deviation of each test in the four subjects were as follows: Cold Immersion: systolic, $26 \pm 10$ ) (liastolic, $33 \pm 9$; pulse, $-6 \pm 7$. Breath-Holding: systolic, $5 \pm 10$; diastolic, $7 \pm 10$; pulse, $5 \pm 11$. Exercise: systolic, $15 \pm 11$; diastolic, $-16 \pm 14$; pulse, $50 \pm 7$. To obtain the standard error of each mean, the standard deviation is divided by $\sqrt{24}=4.9$.

b. Responses of Adult Subjects With and Without IIypertension.-. The mean responses of each group to each test are listed in Table II. The range of individual responses is shown in Fig. 1. There appears to be no consistent difference in the response of the normotensive, labile, or established hypertensive subject, nor between these groups and the groups of children (Croups I, II, and III).

Table II. Mean Test Responses of the Study Grouys

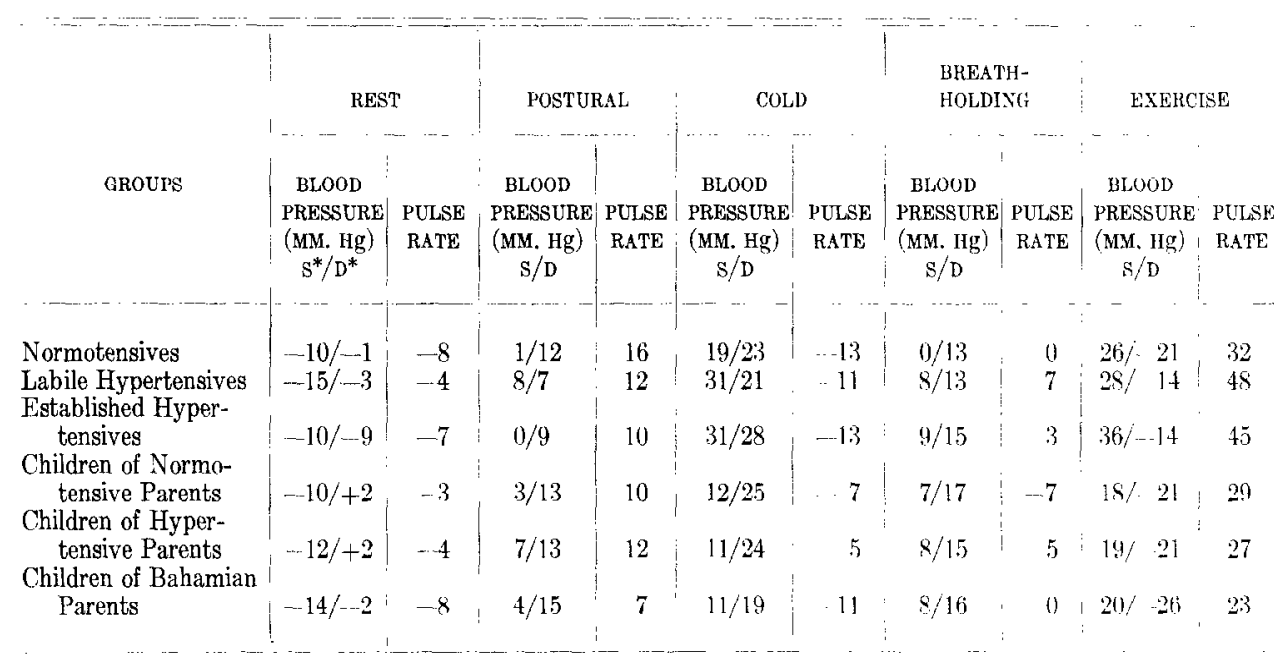

*S $=$ Systolic. $\mathrm{D}=$ Diastolic .

Rest response represents the decline in blood pressure between final recumbent reading (reading No. 9 in Fig. 2) and the first recumbent reading (No. 2). Postural response is defined as the first standing reading in the postural tesi (No. 10) minus the final recumbent reading (No. 9). Cold response represents the difference between the reading after 60 seronds of ice-water immersion (No. 17) anil the pressure immediately prior to immersion (No. 15). Breath-holding and exercise responses likewise represent the difference in blood pressure after and before maximum stimulation (Nos. 23-22 and Nos. 29-28. respectively).

It was recugnized that the rest period prior to cold immersion was abbreviated and that a greater response might have appeared if this part of the test had not been omitted. However, if the reading after 23 minutes of rest (No. 17) is subtracted from the maximum rise after ice-water stimulation (No. 9), the increments in blood pressure due to the cold stimulus are not greatly different and the averages for each group are: Normotensives $=24 / 25$, Labile Hypertensives $=31 / 25$, Established Hypertensives $=$ $42 / 33$, Children of Normotensives $=18 / 30$, Children of Hypertensives $=21 / 29$, and Children of Bahamian Parents $=15 / 22$.

c. Blood Pressures of the Offspring of Normotensive and Hypertensive Parents.Table II and Figs. 2, 3, and 4 present the mean systolic and diastolic blood pressure and the mean pulse rates of Groups I, II, and III at various points in the test procedure. The order of statistical significance of the differences in blood pressure and pulse readings between Groups I and II is indicated at the bottom of the figures. It will be seen that the offspring of hypertensive subjects (Group) 
II) had a higher average systolic pressure and a lower average pulse rate than did their counterparts in Group I, and that these differences were statistically significant $\left(P^{P}<.05\right)$ at nearly every point in the test procedure. In contrast, the diastolic blood pressures of the two groups did not differ significantly from each other.

It may be noted in passing that the "potentially hypertensive" young people exhibited the widest deviation from the offspring of normotensive parents in sistolic blood pressure readings Nos. 14, 15, and 26. At these points the difference between the respective mean systolic readings were of the order of $8 \mathrm{~mm}$. $\mathrm{Hg}$. The probability was less than one in a thousand that these differences were due to chance. The readings taken just before the cold pressor test (Nos. 14 and 15) might be considered to reflect an undue rise in blood pressure in the prehypertensive group as a result of the contemplation of an ensuing unpleasant stimulus.

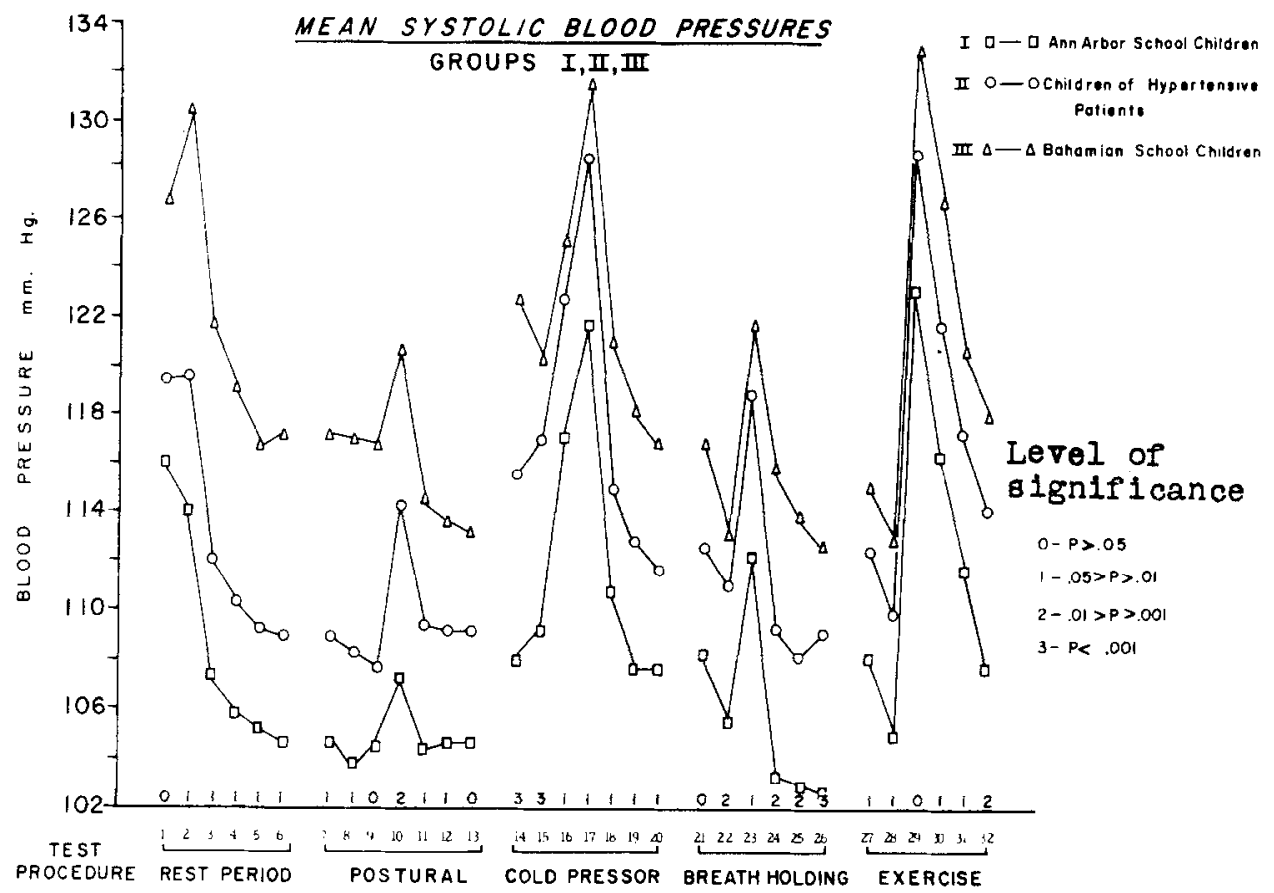

Fig. 2,--1)n the horizontal scale the degree of significance of the differences between readings for Groups [ and II is recorded. Although Group III is included for comparison, the selection of the Bahamian Negro children was less rigorously controlled and the status of blood pressure of the parents was unknown.

However, no such excessive reaction was observed prior to the postural or exercise tests. It is also of interest to note that no significant difference between the group means was observed in the casual reading taken with the subjects standing (No. 1), in the final observation on resting recumbency (No. 9), and in the reading taken immediately after exercise (No. 29).

On further analysis it was found that the five individuals in Group II with the highest resting systolic blood pressure readings tended to show less fluctuation at every point in the test series, whereas those subjects with lower resting blood 
pressures were found to exhibit greater variability from test to test. These observations are of interest since not all subjects in (iroup II may be expected to develop hypertension, but those with the highest bloorl pressure would secm a priori to be the most likely candidates.

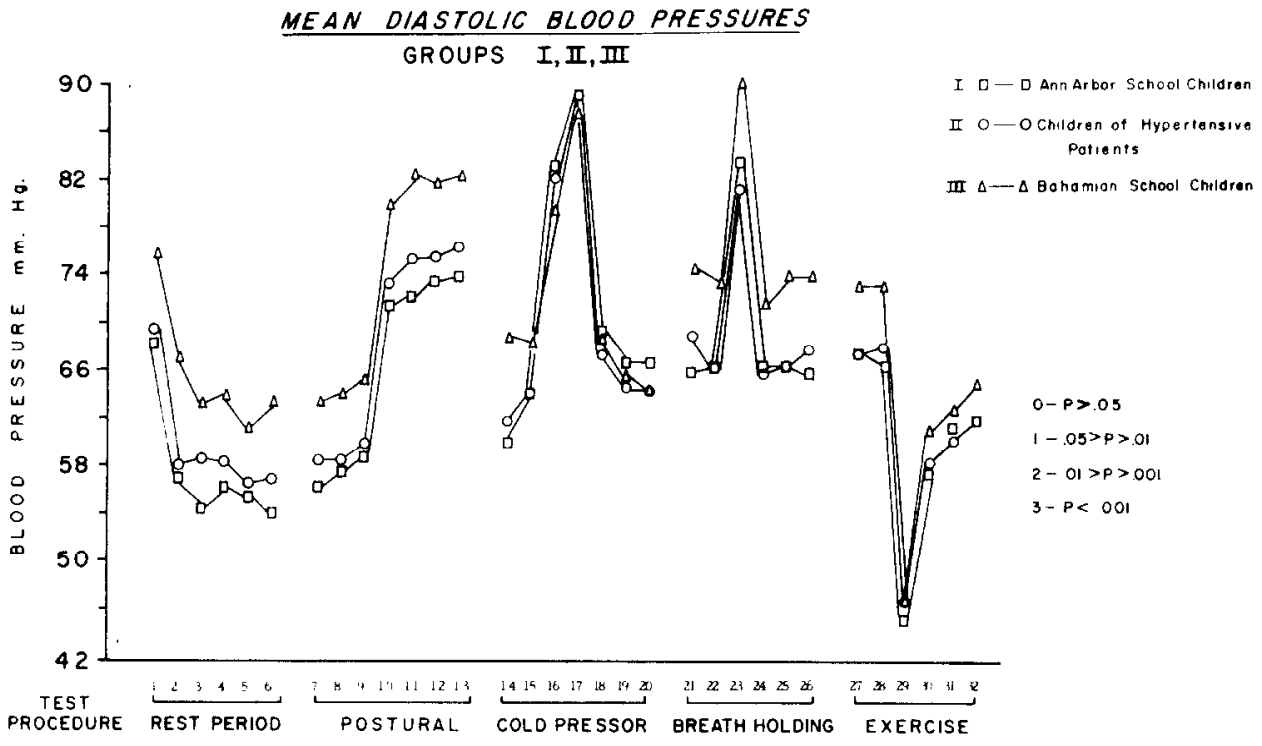

Fig. 3.-Details are as in Fig. 2. No significant difference between croups I and II is observed.

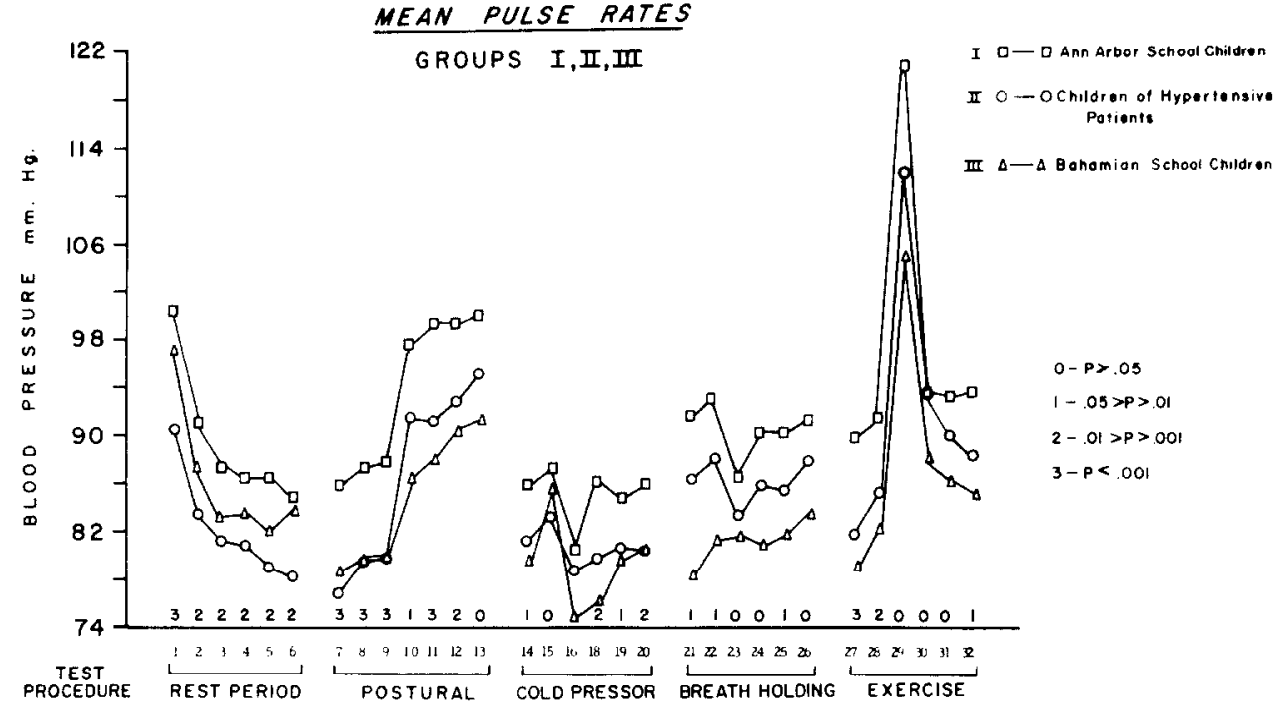

Fig. 4.-Details are as in Fig. 2.

The Bahamian subjects were not included in the statistical comparison because the test conditions were somewhat different, and because they were not individually matched with the subjects in Group I, although they were of similar age and sex distribution (Table I). Nevertheless, Fig. 2 shows that the 
mean systolic blood pressure of these subjects was slightly higher at every point in the series than that recorded for Group II, and considerably in excess of that for Group I. Their mean pulse rate (Fig. 4) was lower than that of Groups I or II, whereas no difference in diastolic levels was observed. These observations, carried out under quite different surroundings, are also consistent with the view that a higher average blood pressure has already become apparent in this group of "potentially hypertensive" subjects.

An analysis of the test responses of the paired groups and of the Bahamian children is also recorded in Table II and in Figs. 2-4. No significant difference in vascular reactivity between Groups I and II could be detected, except that in the postural test, Group II showed a significantly $(\mathrm{P}<.05)$ greater rise in mean systolic blood pressure than did Group I.

d. Relation of Physical Characteristics of the Children to the Blood Pressure Reading.-The possibility that group differences in age, arm girth, or sex influenced the results was considered. A study of the cocfficients of regression for each variable demonstrated no significant trend with age or arm girth for any age-sex subgroup, but the small number involved in these subgroups $(N=14$ to 24) made the demonstration of a significant difference improbable even if small effects had existed.

Inspection of the data recorded in graphic form showed a slight tendency for the mean blood pressure to increase with age. This change occurred equally in Groups I, II, and III. The increase was not the direct result of increased arm girth or of an unusual increase in blood pressure in either boys or girls. The slight increase in the mean blood pressure with age appeared to result more from a few higher individual readings than from a general upward tendency for all subjects. The few individuals under the age of 11 showed generally lower readings. In six of these a child-size cuff was used. Since these impressions are derived from small samples and within a very limited age range, it is of course impossible to draw any conclusions concerning the effects of these physical factors on the blood pressure readings except to state that they did not appear to be responsible for the observed differences between the three groups.

DISCISSION

Fiom these studies it is concluded that the response to no test or combination of tests which we used is characteristic of the hypertensive as compared to the normal individual. Whereas in established hypertensive subjects, abnormal reactivity to pressor stimuli might be obviated by permanent vascular changes, the tests in labile hypertensive patients should demonstrate abnormal responses if increased reactivity is a characteristic of "early" hypertension. The presence of a number of hyporeactors among labile hypertensive subjects certainly indicates that these tests do not consistently identify the labile hypertensive subject.

It is possible that some factor in the selection of control subjects obliterated differences in the reactivity of the various adult groups tested. The rise in blood pressure of the normal subjects in response to cold immersion was, in fact, greater than that reported by Hines and Brown ${ }^{9,10}$ for normotensive individuals. 
Laboratory workers in a hospital might be expected to show less reaction to such stimuli than would unselected normal subjects. The shortening of the rest interval might result in a higher "pre-test" blood pressure in the hypertensive than in the normal subject, so that differences would be abolished. 'To evaluate this possibility we calculated the difference between the blood pressure taken after 60 seconds of cold stimulation ( No. 17) and the blood pressure recorded after 23 minutes of quiet recumbency ( $N$ o. 9). These differences did not help to separate the normotensive, labile, and established hypertensive groups. We must conclude, therefore, that no single test is useful in identifying the hypertensive subject. This conforms with the experience of others. ${ }^{7}, 11,1$ ?

In consequence, it would not be expected that the children of hypertensive parents would display hyperreactivity to similar stimuli. A close examination of the responses of the children with the highest resting blool pressures likew ise revealed that these potentially hypertensive subjects showed no evidence of consistent vascular hyperreactivity.

It was of interest, however, to observe a higher mean systolic blood pressure in the children of hypertensive parents. Moreover, inspection of the data provided by Miall and Oldham ${ }^{1}$ reveals a similar tendency. Twenty-nine children having a parent with a blood pressure of $150,100 \mathrm{~mm}$. Hg or more were compared with 72 children whose parents had blood pressures not higher than 140/90 $\mathrm{mm}$. Hg. The children having one hypertensive parent had mean systolic and diastolic blood pressures of $119 / 74 \mathrm{~mm}$. Hg, whereas the corresponding means for the children of normal parents were $112.72 \mathrm{~mm}$. Hg. The systolic means are highly significantly different $(\mathrm{P}<.005)$, whereas the diastolic means are not significantly different $(.20>\mathrm{P}>.10)$. It is interesting to note how closely these observations of Miall and Oldham parallel those of the present study.

Such comparable results lend greater support to what would at first glance appear to be only slight differences in the blood pressure of the offspring of hypertensive subjects. After prolonged rest, the children of a hypertensive parent had a mean blood pressure of $108 / 60 \mathrm{~mm}$. Hg as compared to $104 / 59 \mathrm{~mm}$. Hg for the offspring of normotensive parents. The difference in mean systolic pressure achieves statistical significance $(P \leqq .05)$. Furthermore, since a consistent and significant difference was tound in almost every one of the 32 consecutive systolic readings, it is hardly likely that the differences were due to chance alone. It is of further interest that the maximum difference $(8 \mathrm{~mm}$. Hg) between the $\mathrm{H}$ wo groups occurred in the blond pressure just prior to the cold pressor stimulus; it suggests that the blood pressure response to a mental stimulus may be excessive in the potentially hypertensive as opposed to the normal subject.

The possibility that intentional bias on the part of the examiner led to the observed differences seems unlikely because of the failure to observe differences in the diastolic blood pressure. If the children of hypertensive parents were more apprehensive about the tests and thus displayed a higher blood pressure, one would expect a greater mean pulse rate in this group. That the contrary was observed would seem to dispose of this objection. The evidence therefore seems convincing that teen-age children with a single hypertensive parent already exhibit a tendency to a higher average sustolic blood pressure. 
If the expected frequency of future hypertension in children with one hypertensive parent were about 30 per cent, ${ }^{3}$ then 70 per cent of the subjects in Group II should behave normally, and only a slight elevation in the mean blood pressure would be expected to appear. The characteristics of the five individuals in Group II (those of hypertensive parentage with the highest resting systolic blood pressure levels) were contrasted with the characteristics of the five children of Group I who had the highest resting systolic pressures. Those in Group II had a resting systolic reading in excess of $118 \mathrm{~mm}$. $\mathrm{Hg}$ as compared to $104 \mathrm{~mm}$. $\mathrm{Hg}$ for those of Group I, the control group. They tended to remain consistently at the top of Group II during stimulation and during rest.

The presence of a higher average systolic blood pressure and a lower pulse rate in the children of hypertensive parentage is the most important finding in this study. It is especially interesting that this difference is maintained under all forms of stimulation tested, and during rest, whether sitting, standing, or lying. Both the Michigan and Bahamian study groups show this characteristic. It is possible that a slow pulse rate was the primary abnormality which resulted in a higher stroke volume and, as a consequence, an increased systolic blood pressure. It would then be necessary to assume that bradycardia is an early sign of hypertension. Since a slow pulse is not seen in manifest forms of hypertension and is, in any event, unlikely to affect cardiac output and pulse pressure to the extent observed, such a hypothesis seems improbable.

An increase in stroke volume might be considered a primary event in the genesis of hypertension. This theor ${ }^{18}$ once widely held has since been abandoned in view of anatomic and physiologic evidence for an increase in peripheral resistance in hypertension.

A third explanation might be that a slight increase in vascular rigidity is already apparent in the offspring of hypertensive parents, and that this leads to a widened pulse pressure and reflex cardiac slowing. Conway ${ }^{19}$ has suggested that some subjects with hypertension, in whom a family history of the disease is prominent, may, in fact, exhibit high blood pressure because of altered arterial and arteriolar elasticity rather than as a result of functional arteriolar vasoconstriction.

These hypotheses concerning the pathogenetic mechanism of familial hypertension must remain speculative so far as the present study is concerned. 'The principal conclusion to be derived from this report is that response of the blood pressure to stimulation is certainly no more indicative, and possibly even less indicative, of latent or overt hypertension than is the actual level of systolic blood pressure.

\section{CONCLUSIONS}

1. Four tests of vascular reactivity-postural change, cold immersion, breath-holding, and exercise - were applied to 10 normotensive, 10 labile hypertensive, and 9 fixed hypertensive subjects. No consistent differences between the groups were obscrved.

2. The same tests were applied to 50 children, aged 8 to 18 , of hypertensive parents matched with 50 children of normal subjects. They were also applied to 
31 Negro children of comparable age in an area with a high prevalence of hypertension. No evidence of unusual vascular hyperreactivity was observed in children of hypertensive parentage, with the possible exception of the response of systolic blood pressure to postural change.

3. The mean systolic blood pressure of the offspring of hypertensive parents was significantly higher at all stages of testing than that of the children of normotensive parents. Furthermore, an analysis of published reports of the data of other investigators confirms that a slight but statistically significant elevation of systolic blood pressure occurs in the youthful offspring of hypertensive subjects.

4. The pulse rate of the children of hypertensive parents (Group II) was significantly lower than that of the children of normotensive parents (Group I), but the mean diastolic pressure of the groups did not differ. Possible explanations of these observations are discussed.

5. It is concluded that a systolic blood pressure in the high "normal" range appears at puberty in certain offspring of hypertensive parents, but that conventional tests of vascular reactivity are not of great usefulness in selecting children likely to develop hypertension.

APPENDIX

Protocol for Blood Pressle Reactivity Tiests

IEST PROCEDURE

PROCEDURAI, STEP

Subject enters room

Subject lies on bed

Rest Period

After 5 minutes' rest

After 10 minutes' rest

After 15 minutes' rest

After 20 minutes' rest

After 21 minutes' rest

After 22 minutes' rest

After 23 minutes' rest

Postural Test Subject stands

After standing 1 minute

After standing 2 minutes

After standing 3 minutes

Cold Pressor

Test
Subject lies on bed

Cold pressor test explained

After explanation

Ice water brought in

3 minutes after explanation

Right hand immersed in ice water

After 30 seconds' immersion

After 60 seconds' immersion

After removal of hand from water

1 minute after removal

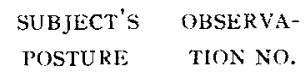

Standing $\quad 1$

Lying ?

Lying 3

Lying 4

Lying 5

Lying 6

Lying 7

Lying 8

Lying 9

Standing 10

Standing 11.

Standing 12

Standing 1.3

Lying

Lying

Lying 14

Lying

Lying $\quad 1.5$

Lying

Lying $16 \quad$ Blood pressure only

Lying $17 \quad$ Blood pressure only

Lying $\quad 17$ Pulse rate only 
2 minutes after removal

3 minutes after removal

Breath-Holding Subject sits in chair Test

After explanation
3 minutes after explanation
Subject holds breath
After 20 seconds' breath-holding
After resumption of breathing
1 minute after resumption
2 minutes after resumption
3 minutes after resumption
Exercise Test
Exercise test explained
After explanation
3 minutes after explanation
Subject exercises (30 deep knee bends)
Immediately after exercise
1 minute after exercise
2 minutes after exercise
3 minutes after exercise

Lying $\quad 19$

Lying 20

Sitting

Sitting

Sitting 21

Sitting 22

Sitting

Sitting 23

Sitting 23

Sitting 24

Sitting 25

Sitting 26

Sitting

Sitting $\quad 27$

Sitting 28

Standing

Sitting 29

Sitting $\quad 30$

Sitting 31

Sitting $\quad 32$

The cold pressor test, breath-holding test, and exercise test were given to our subjects in a preselected, random order, determined by consulting a random number table. The numbers in the column headed Observation No. refer to Figs. 2, 3, and 4, and are also discussed in the text.

\section{REFERENCES}

1. Miall, W. E., and Oldham, P. D.: A Study of Arterial Blood Pressure and Its Inheritance in a Sample of the General Population, Clin. Sc. 14:459, 1955

2. Hamilton, M., Pickering, G. W., Roberts, J. A. F., and Sowry, G. S. C.: The Aetiology of Essential Hypertension. IV. The Role of Inheritance, Clin. Sc. 13:273, 1954.

3. Ayman, D.: Added Evidence of Heredity in Arteriolar Essential Hypertension. Medical Papers Dedicated to Henry Asbury Christian, Baltimore, 1936, Waverley Press, Inc., p. 291.

4. Weitz, W.: Zur Atiolugie der genuinen oder vasculären Hypertension, Ztschr. klin. Med. $96: 151,1923$.

5. Hines, E. A., Jr., Mcllhaney, M. L., and Gage, R. P.: A Study of Twins With Normal Blood Pressures and With Hypertension, Tr. A. Am. Physicians 70:282, 1957.

6. Hines, E. A., Jr.: Vascular Reactivity and Hypertensive Disease. In Hypertension: A Symposium, Minneapolis, 1951, University of Minnesota Press, p. 331

7. Harlan, W. R.: Long-Term Studies of Blood Pressure: Prognostic Reliability of the Cold Pressor Test and Observation on Blond Pressure Variation, Circulation 18:733, 1958.

8. Armstrong, H. G., and Rafferty, J. A.: Cold Pressor Test Follow-Up Study for Seven Years on 166 Officers, Am. Heart J. $39: 484,1950$.

9. Hines, E. A., Jr., and Brown, G. E.: A Standard Stimulus for Measuring Vasomotor Reactions: Its $\Lambda$ pplication in the Study of Hypertension, Proc. Staff Meet. Mayo Clin. $7: 332,1932$.

10. Hines, E. A., Jr.: The Significance of Vascular Hyperreaction as Measured by the ColdPressor Test, Am. HearT J. 19:408, 1940.

11. Pickering, G. W., and Kissin, M.: The Effects of Adrenaline and of Cold on the Blood Pressure in Human Hypertension, Clin. Sc. 2:201, 1936.

12. Alam, M., and Smirk, F. H.: Blood Pressure Raising Reflexes in Health, Essential Hypertension, and Renal Hypertension, Clin. Sc. 3:259, 1938.

13. Ayman, D., and Goldshine, A. D.: Cold as a Standard Stimulus of 'Blood Pressure. A Study of Normal and Hypertensive Subjects, New England J. Med. 219:650, 1938.

14. Ayman, D., and Goldshine, A. D.: The Breath-Holding Test. A Simple Standard Stimulus of Blood Pressure, Arch. Int. Med. 63:899, 1939.

15. Varnauskas, E.: Studies in Hypertensive Cardiovascular Disease, With Special Reference to Cardiac Function, Scandinav. J. Clin. \& Lab. Invest. 7: Supp. 17, 1955. 
10. Snithwick, R. H., and Robertson, C. W.: 'The Phenomenon of Hyperreartivity: 1)efinition and Illustrations, Angiology 2:143, 1951.

17. Kohlstaedt, K. G., Moser, M., Francis, T., Jr., Neel, J., and Moore, F.: l'anel Discussion on Genetic and Envirnmental Factors in Human Hypertension, Circulation 17:728, 1958.

18. Geigel, R.: Die Mechanik der Herzhypertrophie, Arch, path. Anat. 229:353, 1921

19. Conway, J. A.: Vascular Reactivity in Experimental Hypertension Measured After Hexamethonium, Tniversity of Michigan Conference on Hypertension, Circulation 17:807, 1958. 